\title{
PSYCHODEMOGRAPHIC FACTORS INFLUENCING SOCIAL WELLBEING AMONG MOBILE POLICE FORCE IN KWARA STATE, NIGERIA
}

Authors: Rotimi Oguntayo, Oladele Abayomi Olaseni, Johnson Tunde Oyeleke, Helen Okiafe Osinowo

Submit Date: 25 November 2019

Accept Date: 06 March 2020

@ International Journal of Behavioral Sciences-1911-1168ID: IJBS-1911-1168 (R1)

\section{Department of psychology, Faculty of Social Sciences, University of Ilorin, Department of Psychology, Faculty of Social Science, University of Ilorin, llorin, Nigeria}

Department of Psychology, The Faculty of Social Sciences, University of Ibadan, Ibadan

\begin{abstract}
Introduction: There is overwhelming evidence on the increase of dysfunctional social wellbeing among service members returning from deployment, and this is culminating into wide range of social challenges. The study investigated psycho-demographic factors influencing social wellbeing among mobile police force in Kwara State, Nigeria..

Method: The study adopted a survey method utilizing an ex-post-facto design; purposive sampling technique was used to sample 200 mobile police officers ( 152 males and 48 females). They completed a questionnaire pack which included-the Post-Deployment Readjustment Inventory Scale, Emotion Regulation Questionnaire and Mental Health Continuum of Social Wellbeing-Short Form. Data were analysed using descriptive statistics, Pearson Product Moment Correlation, ANOVA and Multiple Regression.

Results: Findings showed that emotion regulation has positive relationship with social wellbeing. Also, age, emotion regulations and post-deployment stress as a whole did significantly predict social wellbeing among the sampled participants. However, emotion
\end{abstract}


regulation did independently predict social wellbeing, though marital status did not significantly influence social wellbeing among the participants.

Conclusion: The study present emotion regulation as a great predictor of social wellbeing. It is recommended that; emotion regulation should be built into the training and debriefing of mobile police before and after deployment to aid their better social wellbeing.Is.

Keywords: Age, Emotion Regulation, Police, Post-deployment stress, Social Wellbeing,

\section{Introduction}

A lot of researches have contributed to the understanding of general wellbeing, however, there is still an increasing number of dysfunctional social wellbeing as a subdomain of general health especially among veterans; service members and those returning from deployment requires support from family, society and friends $[1,2]$. Social wellbeing is a construct focusing on ability of human to maintain good relationship with others, sustain social stability and functioning within the society [3]; this concept explains why human beings are social creatures who collectively depend on others for survival in matter of wellness, relationship, needs, services and connections. Despite the importance of this phenomenon to individuals with the public, low or no study has investigated factors mitigating the social wellness of police in Nigeria. The recent decline in police dyadic relationship with citizens in Nigeria has trigger the need to examine the psycho-demographic factors influencing their social healthiness.

According to a study, social wellbeing is very much of a collective project that an individual cannot experience by his or herself rather, it requires engaging a system of consensual understanding and practices as well as depending on other individuals, utilise social connections and relations in order to sustain wellness [4]. Thus, by focusing solely on individual ability, we may ignore the fact that human lives depend on the way he/she lives and on the characteristics of society we live in. A study has shown that, the quality of relationship is a vital element to increase individual wellbeing cannot be overemphasized [1]. For instance, the 
degree of interdependence in human has a positive effect on social well-being of individuals especially the military and paramilitary officers who deals with society to foster adequate security and safeguard lives and properties.

A study revealed that, well connected individuals are happier and have a stronger impact on the society than the less connected ones [4]. This analysis suggests that how individuals relate with others may provide important information for the intersection of individual wellbeing and societal progress. Added to that, World Health Organisation has defined social wellbeing as a condition in which the individual realizes his or her own abilities to cope with stresses that arise from life, can work productively and fruitfully with people in order to be able to make a positive impact in one's environment [5]. The Nigeria police force have a track record of unleashing mayhem on both innocent harmless citizens and their family [5]. The recent indiscriminate and extra-judicial killing, brutalization and extortion of harmless Nigerians by these law enforcement agents are products of long-standing neglect of researching on psychosocial causes of low social wellbeing among militaries. Brutality cannot be separated from the postdeployment stress as aftermath a consequence among paramilitary and military personnel like police [6]. The inadequate social wellbeing among military may pose the effrontery to engage in unprofessional conducts without remorsefulness or feeling of unprofessional conduct among the mobile police.

The Mobile Police force was is a subsidiary of Nigeria Police Force to foster adequate security, combat sudden unrest and criminality among armed banditry, insurgents, violent militant groups, violent religious sects, and many other agencies of antisocial activities [7]. When mobile police are to return back home from operation, it can be seriously distressing for some of them; in some situations, various psychological factors may set in, such as homecoming stress. Consequently, currently returned mobile police may feel disconnected from the rest of the society, co-officers and family members. Situation like this could trigger internaland/or explicit-personal changes and social skills that may probably lead to poor quality of 
social welling. This issue has led to the need to understand how post-deployment stress associate with social wellbeing.

Looking at aftermath effects of post-deployment among mobile police, their performance or optimal productivity in the services render could be affected as no robust social wellbeing is achieved because of the post-deployment stress [8]. Thus, identifying whether post-deployment stress is specifically a key for determining social wellbeing among the mobile police is needed. In addition, a group of scholars define redeployment as the situation when a service member departs from a combat mission and ending at the service member's stateside and reintegrated to his/her colleagues $[8,9]$. The period that directly followed the return of military personnel from deployment, do cause experience of Post-traumatic stress disorder (PTSD) and its symptoms such as extreme interpersonal difficulties, poor anger management, difficulties in coping and hyper-vigilance social withdrawal, increased alcohol use, heightened symptoms of depression and heightened symptoms of anxiety [8]. Another study put it that, post-deployment stress occurs after personnel experience severe trauma or a life-threatening event, while post-deployment stress develops differently from veteran to veteran [10]. In postdeployment stress event, emotional feelings may arise, such as; the goals that give rise to emotions, dyadic relationships, and regressive work-related skills; the ability to regulate this emotion determines human level of social wellbeing. Emotions regulation has been discovered to promotes wellbeing in individuals [11]. In addition, individuals who recognize his/her emotions and can regulate his/her emotions could practice discretion in their behaviors, and comprehend emotion regulation skills to use at a point especially when facing social inadequacy [10]. Unfortunately, no literature has explored this construct among Nigeria mobile police in order to enhance their social healthiness. This introduces emotion regulations into social wellbeing.

Emotion regulation involves changes in how response components are interrelated as the emotion unfolds, such as when increases in physiological responding occur in the absence 
of overt behaviour [12]. A study discovered that adults do report high and positive emotion regulations when interacting with their social partners than do younger adults [11]. Although, losses of close networks members occur, for many older adults than the number of close confidants and amount of social support remains the same throughout later adulthood[11]. Compared to military men who are married, adult women who are married, maintain more same-sex close relationships[12,13]. It has been discovered in various literature that married persons have greater psychological and social well-being than their single counterparts $[11,12,13]$.

This study, therefore examined the influence of psycho-demographic factors (postdeployment stress, emotion regulations, age, gender and marital status) on social wellbeing among mobile police in kwara state, Nigeria. Thus, two hypotheses have been considered in the current study. The hypotheses was stated thus; i. age, emotion regulation and post-deployment stress will jointly and independently significantly predict social wellbeing among the sampled participants, ii. individuals who are married will score high significantly on social wellbeing compare to the single and the divorced.

\section{Methods}

This study adopted a survey method utilizing an expost-facto design. This is because the variables in the research have not been manipulated. The independent variables were age, marital status, post-deployment stress and emotion regulation while the dependent variable was social wellbeing. Two hundred mobile police who volunteered to participate in this study having signed the inform consent were purposively selected through a non-random sampling in their base in Kulende (MOPOL 49), llorin, Kwara state, Nigeria. These individuals are most suitable for this type of study because they possessed the characteristics expected in events under investigation.

Demographic Data Form: Respondents demographic information are as follows; Respondents were 176 with 152(76.0\%) were male while 48 (24.0\%) were females. Also, 85 
(42.5\%) were Christians and 115 (57.5\%) were Muslims. In terms of tribe, 35 (17.5\%) were Igbo, 76 (38.0\%) were Hausa and others from minority tribes were 20 (10\%). Regarding their marital status, 74 (37.0\%) were single, 123 (61.5\%) were married and 3(1.5\%) were divorced. Also, 179 (89.5\%) were young adult and $21(10.5 \%)$ were middle age adult. However, participants' names were excluded for the sake of confidentiality and to ensure sincere completion of the measuring index.

Post-Deployment Readjustment Inventory Scale (PDRI): Post-deployment stress was assessed utilizing PDRI [14]. It was designed to as a self-report questions on symptoms and level of functioning across a variety of domains of post-deployment stress that veteran can encounter after returning from deployment. It uses a 5-point Likert-type scale thus; 1=not at all,

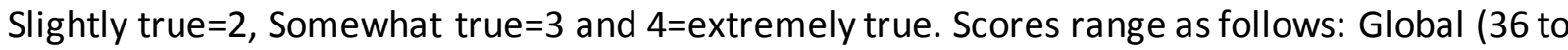
180), Career Challenges (5 to 25), Social Difficulties (7 to 35), Intimate Relationship Problems (5 to 25), Health Concerns (5 to 25), Concerns About Deployment (6 to 30), and PTSD Symptoms (8 to 40). Scoring is the sum of the following items: Career =1, 6, 13, 23, 34; Health= 2, 8, 11, 14, 30; Intimate relationship=5,15,17,31,35; Social readjustment=3, 7,19,22,25,27,33; Concerns about deployment=9,12,16,28,36,26; PTSD symptoms=4, 10,18,20,21,24,29,32; Total score sum of all scales [22].The Cronbach Alpha recorded for the present study was .78 .

Emotion Regulation Questionnaire (ERQ): ERQ is 10-item scale designed to examine respondents' tendency to regulate their emotions in two ways: (1) Cognitive Reappraisal and (2) Expressive Suppression [15]. The scale involves two distinct aspects of emotional life. One is what person feel like inside. The other is how individuals show their emotions in the way they talk, gesture or behave. Respondents answer each item on a 7-point Likert-type scale ranging from 1 (strongly disagree) to 7 (strongly agree). Scoring Norms: Items1, 3, 5, 7, 8, 10 makeup the Cognitive Reappraisal facet. Items 2, 4, 6, 9 made ups the Expressive Suppression facet. Scoring is kept continuous. Each facet's scoring is kept separate. The Cronbach Alpha recorded for the present study was .73 . 
Mental Health Continuum of social wellbeing-Short Form: The Mental Health Continuum-Short Form (MHC-SF) was part of the mental health Module of December 2007[16]. It meant to measure three dimensions; social well-being, emotional and psychological wellbeing. The MHCSF includes 14 items for assessing positive mental health ( 3 items for emotional well-being, 6 items for psychological wellbeing and 5 items for social well-being. The scale for social wellbeing dimension was utilised in this study to assess social well-being. The respondent is asked to rate the frequency of every feeling on a 6 -point Likert scale $(0=$ never, $1=$ once or twice a month, 2=about once a week, 3=two or three times a week, 4=almost every day, $5=$ =veryday).The MHC-SF has a reliability value (Cronbach's alpha) of .89. For the present study Cronbach Alpha recorded was .83. Before handing the questionnaire to each participant, a simple introductory discussion was conducted stating partial intention of the research so as to gain the participant's cooperation and sincerity.

Also, participants were asked to sign the inform consent form attached with the questionnaire; the questionnaires were then, administered. The participants were approached in their various bits, offices and their apartments. It took the researchers several weeks to administer the questionnaire and collect it back.

Data was analyzed using (statistical packages for the social sciences) SPSS 21.0. Descriptive statistics such as frequency, mean, Standard Deviation and variance were performed to describe the subject's information. The reliability analysis of the instruments was ascertained and reported as local reliability for future reference. Pearson Product Moment Correlation, multiple regression and one-way ANOVA was used to analyzed the hypotheses 1 and 2 respectively.

\section{Results}

Table 1 results showed that there is significant positive relationship between emotion regulation and social wellbeing $(r=.277 ; p<.01)$ while there is no relationship between age, post- 
deployment stress and social wellbeing. Hence, the need to regress the independent variables on dependent variable arises as presented below:

Table 2 revealed that age, emotion regulation, and post deployment stress will jointly significantly and independently predict social wellbeing, the result shows that age, emotion regulation and post deployment stress as a whole jointly significantly predict social wellbeing among the sampled participants $\left[R=.69 ; R^{2}=.136 ; F(6,839), t=3.382, p<.01\right]$, the result further revealed that $14 \%$ of the variance observed in social wellbeing was strictly accounted for by age, emotion regulation and post-deployment stress among the respondents. While only emotion regulation $[t=3.89, p<.01, \beta=.269]$ independently predict social wellbeing among the police personnel. Therefore, age, emotion regulation and post-deployment stress did jointly and independently significantly predict social wellbeing among the sampled participants.

Result in Table 3 showed that marital status did not significantly influence social wellbeing among the participants $(F(2,197)=1.178, p>.01)$. It is therefore rejected that, individuals who are married did score high significantly on social well being when compare to other counterparts who are either single or divorced. This was showcased using One-way Analysis of Variance (ANOVA) as presented in table 3.

Table 1: Summary Showing Pairwise Inter-variable Correlations using Pearson Product Moment Correlations

\begin{tabular}{llllllll}
\hline & Variable & 1 & 2 & 3 & 4 & $\bar{x}$ & SD. \\
\hline 1 & Age & - & & & & 29.79 & 6.36 \\
2 & Emotion Regulation & $.172^{*}$ & - & & & 22.69 & 8.38 \\
3 & Post Deployment Stress & $-.144^{*}$ & -.024 & - & & 33.65 & 14.63 \\
4 & Social Wellbeing & .096 & $.277^{* *}$ & -.137 & - & 22.56 & 11.51 \\
\hline
\end{tabular}


**. Correlation is significant at the 0.01 level (1-tailed)

*. Correlation is significant at the 0.05 level (2-tailed).

Table 2: Summary Showing Significant Prediction of Social Wellbeing Linear Regression

\begin{tabular}{lllllll}
\hline Variables & $\mathrm{R}$ & $\mathrm{R}^{2}$ & $\mathrm{~F}$ & Sig. & Beta & $\mathrm{T}$ \\
\hline Age & & & & & .018 & .231 \\
Emotion Regulation & .369 & .136 & 4.34 & .000 & .265 & 3.888 \\
Post Deployment Stress & & & & & -.137 & -1.947 \\
& & & & & & \\
\hline$\quad * * p<.01,{ }^{*} p<.05$ & & & & & &
\end{tabular}

Dependent Variable: Social Wellbeing

Table 3: Showing the significant Influence of Marital Status of Respondents on Social Wellbeing

\begin{tabular}{lllllll}
\hline Source & SS & df & MS & F & P & $\mathrm{np}^{2}$ \\
\hline Marital Status & 311.469 & 2 & 155.735 & 1.178 & $>.01$ & .06 \\
Error & 26037.926 & 197 & 132.172 & & & \\
Total & 26349.395 & 199 & & & & \\
\hline
\end{tabular}

\section{Discussion}

Considering the result of this study, age, emotion regulation and post deployment stress did have a significant joint prediction on social wellbeing. However, only emotion regulation independently predicts social wellbeing among the police personnel. This result supports the previous findings [12]. This implies that the ability of people to modify emotional regulation behavior effectively may help people adapt easily to social demands. Equipped with this ability, individuals might be more successful in communicating attitudes, goals, and intentions that are appropriate in various situations and that might be rewarding, productive and fulfilling in 
dealing with public as police officers [17]. This is similar to a study that found that age combined with emotion regulation are often important determinants of social wellbeing [18]. Researches have shown that Emotion Regulation is a central aspect of people's affective functioning, influencing well-being, positively or negatively as a function of how effectively people manage their emotional responses to everyday events [19, 20,21]. Also, a study found that demographic variables impact employees social wellbeing more [22]. However, there are no results conducted on post-deployment stress as determinants of wellbeing in the past. Notwithstanding, this implies that age could be used to explain social wellbeing that is, probably as individuals increase in age learning may increase too which may consequently increase social wellbeing.

Findings on the postulated statement that, individuals who are married will score high significantly on social wellbeing compare to the single and the divorced was analysed. The results revealed that marital status did not significantly influence social wellbeing. Though some various literatures have put it that, married persons have greater psychological and physical well-being than their single counterparts $[23,11]$. A study found that married persons have larger social networks and greater social support than unmarried persons [24, 13]. Married persons are also more likely than non-married persons to participate in organize situations [12]. However, it was difficult to found a result that is directly similar to this finding as at the time it was conducted. This implies that in para-military settings marital status cannot be used to explain social wellbeing.

\section{Conclusion and Recommendation}

In this study, some specific psycho-demographic factors determining social wellbeing have been examined. This study investigated whether; age, emotion regulation and postdeployment stress will jointly and independently significantly predict social wellbeing among 
the sampled participants, individuals who are married will score high significantly on social wellbeing compare to the single and the divorced among mobile police in the main city of kwara state-Ilorin, Nigeria. After examining 176 mobile police officers, the statistical analysis concluded that, age, emotion regulation, and post deployment stress did jointly significantly predict social wellbeing while only emotion regulation did independently predict social wellbeing among the police personnel sampled. However, results revealed that marital status did not significantly influence social wellbeing among the sample respondents. In this study, age, emotion regulation and post deployment stress have been discovered as one of the psycho-demographic factors to be considered when considering means of enhancing social wellbeing among the police in the sampled area. Although, previous findings from western world indicated that there is marital status difference in the social wellbeing skills but, the present study was able to found contradictory results however, the study was able to explain the reasons behind this disparity in result considering the roles of training and educational qualification in these individuals. Also, future researchers should consider investigating the influence of psychosocial factors especially the roles of education and psychological training (emotion regulation) by involving larger numbers of participants than the present study to ascertain the generalization of the current findings. It is also possible that outcomes would vary if measured over a thousand or more participants.

On the basis of the findings reached in this study, the following measures are suggested in order to increase social wellbeing of police globally and in Nigeria particularly:

1. Police clinicians are to build in emotion regulation modules into intervention when training for mission and/or debriefing after mission.

2. All Military Cadres should integrate psychological knowledge into the training of their personnel, for them to better understand the importance of human relationship, learn how to manage their stress and regulate their emotions to promote greater social wellbeing. 


\section{Conflict of Interest}

None declared

\section{References}

1. Burnell K, Coleman P, Hunt, N. Coping with traumatic memories: Second World War veterans' experiences of social support in relation to the narrative coherence of war memories. Ageing and Society. 2010; 30(1): 57-78.

2. Dodge R, Daly A, Huyton J, Sanders L. "The challenge of defining well-being," International Journal of Well-being. 2012; 2(3): 222-235.

3. Keyes LM. Social Wellbeing. Social Psychology Quarterly. 1998; 61(2): 121-140.

4. Fowler JH, Christakis NA. Dynamic spread of happiness in a large social network: Longitudinal analysis over 20 years in the Framingham Heart Study. British Medical Journal. 2008; 337: 2338-2346.

5. World Health Organization. Promoting Mental Health. Concepts, Emerging Evidence, Practice. Geneva: World Health Organization; 2004.

6. This Day. Nigeria and Police Brutality; April 23, 2019.

7. Olukoya S. Nigeria's trigger-happy police. BBC News; 2001.

8. Cunningham GA, Weber AB, Roberts RL, Hejmanowski ST, Griffin DW, et al. Role of Resilience and Social Support in Predicting Post-deployment Adjustment. Mil Med. 2014; 179(9):979-982.

9. Steenkamp MM, Boasso, AM, Nash WP, Larson JL, Lubin RE, Litz. PTSD symptom presentation across the deployment cycle. Journal of Affective Disorders. 2015; 17(6):87-94.

10. Lazarus RS. From psychological stress to emotions. Annual Review of Psychology. 1993 44:1-21.

11. Shadiya MS, Baqutayan S, Wahidah AG, Mah G. The Relationship between Stress and Emotional Intelligence among Postgraduate Students: The Case Study at Perdana School of Science, Technology and Innovation Policy (STI Policy), University Technology Malaysia. International Journal of Behavioral Sciece. 2017; 11(2):74-81.

12. Dadfarnia S, Hadianfard H, Rahimi C, Aflakseir A. Emotion Regulation Therapy for Social Anxiety Disorder Comorbid with Major Depressive Disorder: A Case Study. International Journal of Behavioral Sciece. 2019; 13(2):68-72.

13. Stroebe W, Stroebe M. Social psychology and health. Buckingham: Open University Press; 1995. 
14. Katz LS, Cojucar G, Davenport CT, Pedram C, Lindl C. Post-Deployment Readjustment Inventory Scale (PDRI). Military Psychology. 2010; 22:41-56.

15. Gross JJ, John OP. Individual differences in two emotion regulation processes: Implications for affect, relationships, and well-being. Journal of Personality and Social Psychology. 2003; 85, 348-362.

16. World Health Organization. World Health Organization Constitution. Basic documents; 1948.

17. Taherifar Z, Frdowsi S, Mootabi F, Mohammad-Ali M, Fata L. Emotion regulation therapy for generalized anxiety disorder comorbid with Major Depressive Disorder: A case study. International Journal of Behavioral Sciences. 2016;10(1):60-5.

18. Addai I, Opoku-Agyeman C, Amanfu SK. Exploring predictors of subjective wellbeing in Ghana: A micro-level study. Journal of Happiness Studies. 2014; 15: 869-890.

19. Keltner D, Haidt J. Social functions of emotions at multiple levels of analysis. Cognition and Emotion. 1999; 13:505-522.

20. Webb TL, Miles E, Sheeran, P. Dealing with feeling: A meta-analysis of the effectiveness of strategies derived from the process model of emotion regulation. Psychological Bulletin. 2012; 138:775-808.

21. Vaillant, G. (2012). Triumphs of Experience: The Men of the Harvard Grant Study. Harvard University Press; 2012.

22. Balogun AG. Demographic variables predicting employee willingness to share tacit knowledge in service occupations. IFE PsychologIA. 2014; 22(2): 42-53

23. Waite L, Gallagher M. A case for marriage. New York: Doubleday. 2000.

24. Tamir M, John OP, Srivastava S, Gross JJ. Implicit theories of emotion: Affective and social outcomes across a major life transition. Journal of Personality and Social Psychology. 2007; 92:731-744. 